\title{
Upper Ocean Response to the Tropical Cyclone Ockhi and its Impact on Primary Production in Arabian Sea
} \author{
Chakrapani $^{2}$ \\ ${ }^{1}$ Indian Institute of Tropical Meteorology, India \\ ${ }^{2}$ Department of Atmospheric Sciences, Cochin University of Science and Technology, India \\ ${ }^{3}$ School of Global studies, University of Sussex, UK
}

S Saranya Ganesh ${ }^{1}$, S Abhilash ${ }^{2 *}$, A K Sahai ${ }^{1}$, Athira $\mathbf{U}^{1}$, S Josepha P ${ }^{1}$, P Vijaykumar ${ }^{2}$, Max Millan ${ }^{3}$ and B

Submission: July 08, 2019; Published: July 29, 2019

Corresponding author: S Abhilash, Department of Atmospheric Sciences, Cochin University of Science and Technology, Cochin, India

\begin{abstract}
This study investigates the upper ocean response and primary productivity over Arabian Sea due to tropical cyclone 'Ockhi', a rare tropical storm system that formed over southwest Bay of Bengal and moved westward into the Arabian Sea while rapidly intensifying into a severe storm. Multi-satellite data products comprising Sea Surface Temperature (SST), turbulent fluxes, surface wind, and Ekman pumping derived from European Reanalysis - 5 (ERA5) daily surface wind data is used to examine the evolution and life cycle of the storm. MODIS derived Chlorophyll-a (Chlor-a), daily averaged Photosynthetically Available Radiation (PAR) and Particulate Organic Carbon (POC) are utilized for detailed analysis of the impact of the storm. Evolution of SST starting from the week prior to Ockhi shows that Southeast Arabian Sea and South-west Bay of Bengal regions had high values ranging from 28 to more than $30^{\circ} \mathrm{C}$, temperatures favorable enough to fuel the intensification of Ockhi. As the storm system moved north-westward, a clear reduction in SST is observed over the west-central Arabian Sea, affirming the upper ocean cooling associated with strong upwelling in the storm centre. A ten-fold increase in Chlor-a concentrations from 0.5 to $5 \mathrm{mg} / \mathrm{m}^{3}$ was observed after the passage of Ockhi, accompanied by a high wind-stress curl. The increase in PAR is primarily driven by reduction in clouds post-cyclone and a corresponding increase in POC concentrations is evident over the cold pool along the trail of storm. The maximum concentration of bloom is observed over central Arabian Sea where Ockhi remained stationary as it recurved under the influence of strong sub-tropical westerlies. The present study concludes that slow progression of Ockhi and its re-curving path contributed to enhanced upwelling through Ekman pumping and uplifting of thermocline which resulted in the reduction in SST and contributed to increase in ocean primary production.
\end{abstract}

Keywords: Arabian Sea; Chlorophyll-a; Tropical cyclones; Remote sensing; Ocean primary production; Ekman pumping

\section{Introduction}

The two major seasons leading to the development of intense cyclonic storms over the North Indian Ocean (NIO) basin are during the pre-monsoon (Apr-May-June) and postmonsoon (October-November-December) periods. In general, cyclogenesis over Arabian Sea occurs either in situ over Southeast Arabian Sea and over the Lakshadweep regions due to upper air circulations resulting from active monsoon troughs or pre-monsoon surges or in rare cases from remnants of cyclones from the Bay of Bengal that move across the south peninsular India because most cyclones that form over Bay of Bengal weaken after landfall (IMD, 2016). In addition, Arabian Sea is relatively colder than Bay of Bengal and hence inhibits the formation and intensification of storms. However, studies have suggested that the warming of NIO in recent decades may lead to increase in the frequency of extremely severe storms over the region [1,2]. Cyclone Ockhi was named an "unusual cyclone with a rare track" by the media and scientific community alike as it was the first storm after 1925 to severely affect the southwestern coast of India that traversed over open sea for more than $2500 \mathrm{~km}$ before landfall (IMD, 2018). Its unprecedented intensification was rapid and near the coastlines resulting in massive destruction of over 10,000 homes along the coast and after its passage, almost 660 unaware fishermen who had ventured into the sea from Kerala, Tamil Nadu and Lakshadweep islands were reported missing. As per IMD records, the only other recorded cyclonic storm to follow a similar track affecting Sri Lanka and southern peninsular India was the one that formed in December 1912.

It has been recognized since the 1930s that lower tropospheric westward traveling disturbances provide the "seedling" circulations for a large proportion of tropical cyclones [3-5]. These are known as easterly waves, which are generally embedded in the trade wind flow in the lower levels of troposphere and are usually observed to occur through October to April with a periodicity of about 3 to 4 days having 
wavelengths of 2000 to $2500 \mathrm{~km}$. Cyclone Ockhi also owes its genesis to such an easterly wave which moved over the Comorin Sea and southeast BoB on 28 November, 2017. By early hours of 29 November, the low pressure developed into a depression, passed over Sri Lanka and intensified into a deep depression moving in a west-northwestward track moving towards the south coast of India. The storm then underwent rapid intensification and developed from deep depression into a Very Severe Cyclonic Storm (VSCS: maximum sustained wind speed greater than 64 knots) by December 1, 2017 and slowly moved over the Lakshadweep islands into southeast Arabian Sea. Ockhi maintained its intensity till early December 3 , as it moved towards northwest. Between December 3 and 4, under the influence of strong upper level westerlies, the storm recurved from east-central Arabian Sea and underwent rapid weakening into a depression, gradually dissipating into a low-pressure area. It made landfall over the South Gujarat coast on $6^{\text {th }}$ of December. Track of Ockhi from 29 November to 6 December is given in Figure 1.

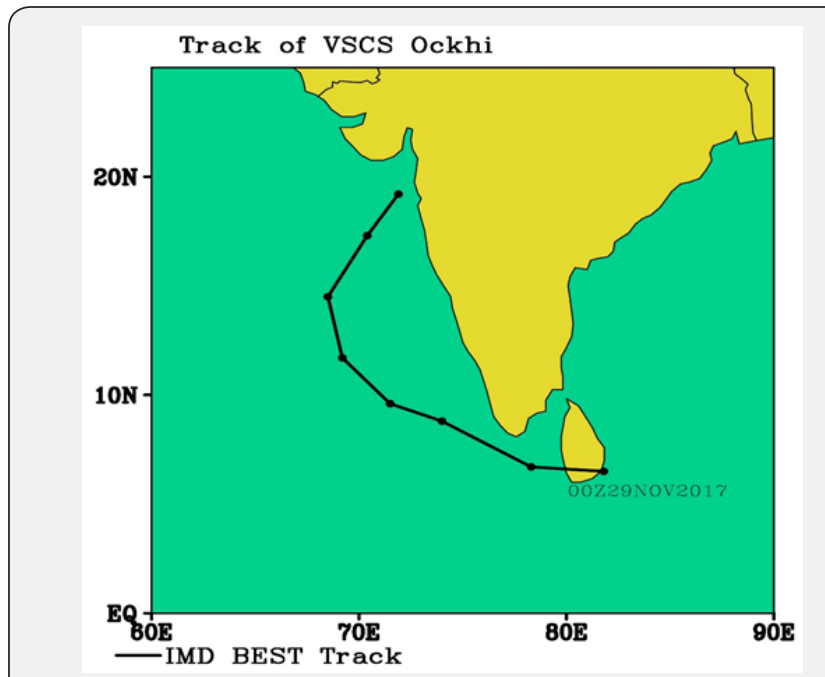

Figure 1: Track of Cyclone Ockhi from 29 November to 5th December 2017

The upper ocean responses associated with tropical cyclones includes reduction in SST along the storm track, changes in thermocline, surface mixed layer depth and associated upwelling [6]. These responses are more pronounced in the cases of slowly moving cyclones. Satellite data has been used extensively to study the ocean responses, ocean-atmosphere interactions and ocean primary productivity due to the passage of tropical storms as in situ observations are difficult during the storms [7-12]. Lin et al. [13] used datasets from the Tropical Rainfall Measurement Mission (TRMM) satelite, SST and NASA QuickSCAT ocean surface wind vectors and showed that the strength of surface wind over the cold SST patches weakens relative to that over surrounding warm SST and this wind speed anomalies continue to exist until the low SST patches disappear. This study highlights the upper ocean response and associated variations, observed over Arabian Sea due to VSCS Ockhi using multi-satellite data.

\section{Data and Methodology}

The NIO basin including both Arabian Sea and Bay of Bengal covering $0-25^{\circ} \mathrm{N}$ and $50-100^{\circ} \mathrm{E}$ is the area considered for the present study. The details of VSCS Ockhi is obtained from storm reports of IMD and Joint Typhoon Warning Centre. ERA-5 daily averaged data sets of $u$ and $v$ components of wind at $10 \mathrm{~m}$ height with a resolution of $1 \mathrm{x} 1$ degree is used to calculate Ekman pumping due to storm. Infrared Brightness Temperature (BT) during the storm period is obtained from Geostationary satellite datasets of National Oceanic and Atmospheric Administration (NOAA) Climate Prediction Centre [14]. Daily SST data (4 km resolution) is obtained from Advanced Very High-Resolution Radiometer (AVHRR-SST) from NOAA. Turbulent fluxes including latent and sensible heat fluxes along with surface wind stress and wind vector data are obtained from Scatterometer Satellite-1 (Scat-SAT1) through Meteorological and Oceanic Satellite Data Archival Centre of Indian Space Research Organization [15]. Scanning Scatterometer is an active microwave device designed to determine ocean surface level wind vectors through estimation of radar backscatter. The Ku-band pencil beam scatterometer is operating at $13.515 \mathrm{GHz}$ providing a ground resolution cell of size $25 \times 25 \mathrm{~km}$.

Chlorophyll-a (Chlor-a), daily averaged Photosynthetically Available Radiation (PAR) and Particulate Organic Carbon (POC) derived from Moderate Resolution Imaging Spectroradiometer (MODIS) [16,17] are used to analyze the variation in ocean primary production before, during and after the passage of Ockhi. Algorithm for MODIS Chlor-a concentration/POC uses an empirical relationship derived from in situ measurements of Chlor-a/POC and blue-to-green band ratios of in situ remote sensing reflectances (Rrs) returning the near-surface concentrations in $\mathrm{mg} \mathrm{m}^{-3}$. The PAR is defined as the quantum energy flux from the Sun in the $400-700 \mathrm{~nm}$ range. Algorithm for MODIS daily mean PAR estimates daily average PAR at the ocean surface in units of einstein $/ \mathrm{m}^{2} \mathrm{day}^{1}$. For ocean colour applications, PAR is a common input used in modelling marine primary productivity. Implementation of this algorithm is contingent on the availability of observed top-of-atmosphere radiances in the visible spectral regime that do not saturate over clouds.

\section{Results and Discussion}

\section{Upper Ocean Response to Ockhi}

Brightness Temperature in infrared spectra of geostationary satellite from 27 November to 6 December is shown in Figure 2. Under favorable conditions, the low pressure concentrated into a depression by 29 November and moved westward crossing Sri Lanka. The storm emerged in the Comorin Sea, intensifying into a deep depression in the early hours of 30 November and moved north-westwards strengthening into a cyclonic storm on the same day moving near the South Kerala and Kanyakumari coasts. The BT near the eyewall during this time is less than 200K. Ockhi intensified further as it crossed Lakshadweep 
Islands on December 1 and became a VSCS over southeast Arabian Sea. It reached peak intensity of more than $150 \mathrm{~km} / \mathrm{h}$ on December 2 with an estimated central pressure of less than 980 $\mathrm{hPa}$. Ockhi maintained its intensity till early hours of December 3 , thereafter, came under the influence of strong subtropical westerly ridge that was present to the north of $14^{\circ} \mathrm{N}$ and started its re-curvature towards north-east and gradually weakened. The storm made landfall near the south coast of Gujarat as a well-marked low pressure in the early morning of $6^{\text {th }}$ December.

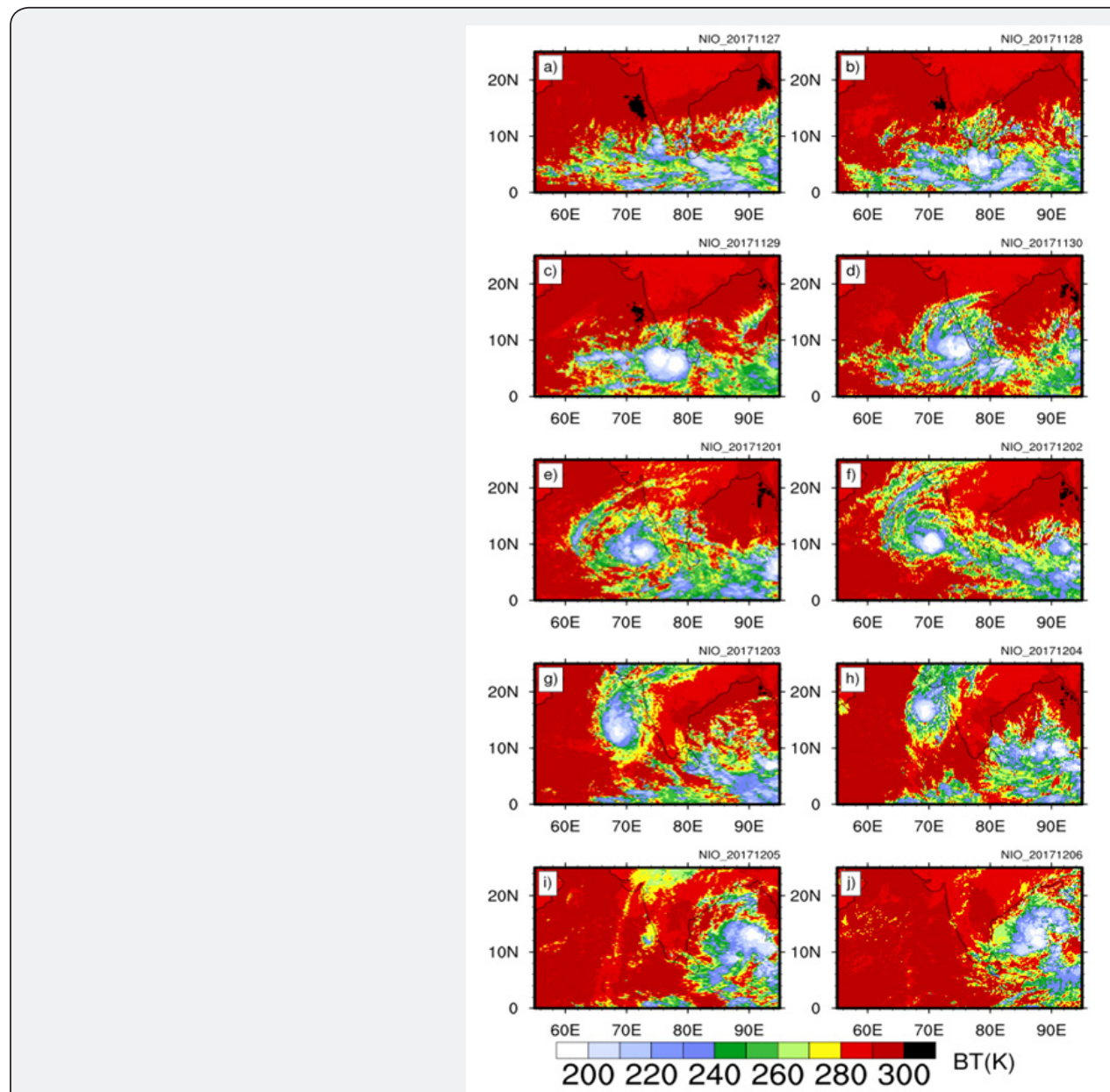

Figure 2: Distribution of AVHRR-SST (shaded) and $10 \mathrm{~m}$ wind vector for VSCS Ockhi over North Indian Ocean from 28 November (a) to 5 December (h), 2017.

Previous studies show that upper ocean cooling is influenced by storm intensity, cyclone translational speed, initial mixed layer depth, Ekman pumping velocity and pre-existing circulation patterns. Montgomery et al. [18] suggested that decreasing translational speed along with high storm intensity can lead to larger upper ocean response. According to IMD, Ockhi had a 12hour average translational speed of $15 \mathrm{kmh}^{-1}$ which satisfies the slow-moving criteria till its mature stage. The storm attained maximum intensity on December 2 and maintained its strength till December 3 before recurving and weakening. SST, surface wind stress and heat fluxes are compared here to understand the upper ocean response to Ockhi. Thus, synergic use of these multi-satellite data sets enables us to understand the physical and dynamical responses of upper ocean during and after the passage of Ockhi.

Figure 3 shows the AVHRR-SST superimposed with surface wind vectors from ScatSAT-1 over NIO from November 29 to
December 5; corresponding Scat-SAT 1 analysed wind stress curl (shaded) and stress vectors are presented in Figure 4. Warm SSTs ranging from 29 to more than $30^{\circ} \mathrm{C}$ over South-East Arabian Sea and in some areas over equatorial Indian Ocean provided favorable conditions for storm development. On $29^{\text {th }}$ November, a strong surface circulation with weak wind stress is evident over Sri Lanka and neighborhood which moved westward over South coast of India by November 30. It may also be noted that there is no significant SST variation in this region after the storm passage. But as the storm progressed north-westwards, a reduction in SST by approximately $1^{\circ}$ is observed over areas left behind by the storm. Figure 5 shows the Ekman transport during the evolution of Ockhi from 28 November to 6 December (left to right) [19]. Strong upwelling is observed along the track of Ockhi throughout its lifetime. As Ockhi intensified and crossed Lakshadweep region, wind stress curl was having its maximum intensity. 

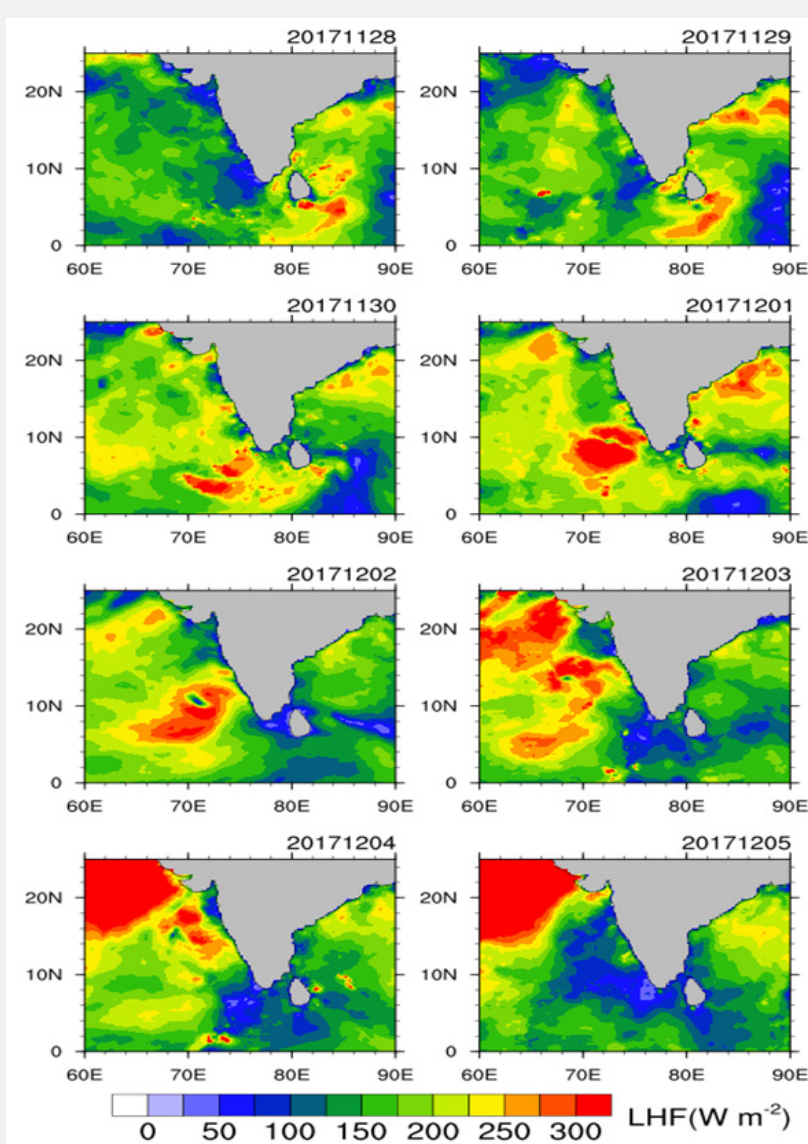

Figure 3: Latent heat flux for Cyclone Ockhi from 28 November to 5 December, 2017.
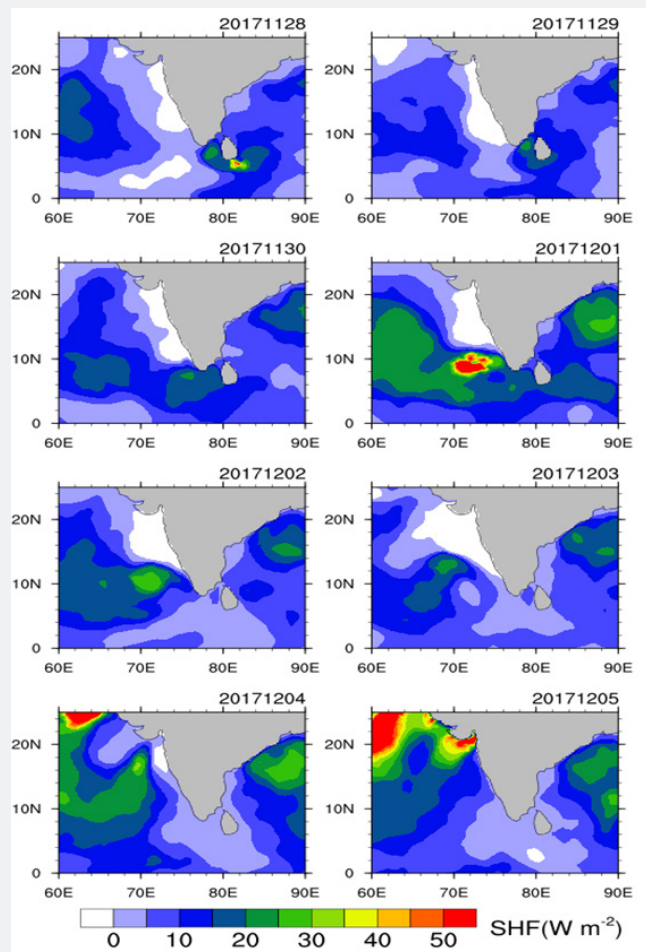

Figure 4: Ekman pumping in $\left(\times 10^{4} \mathrm{~N} / \mathrm{kgs}\right)$ during the life cycle of Ockhi. 


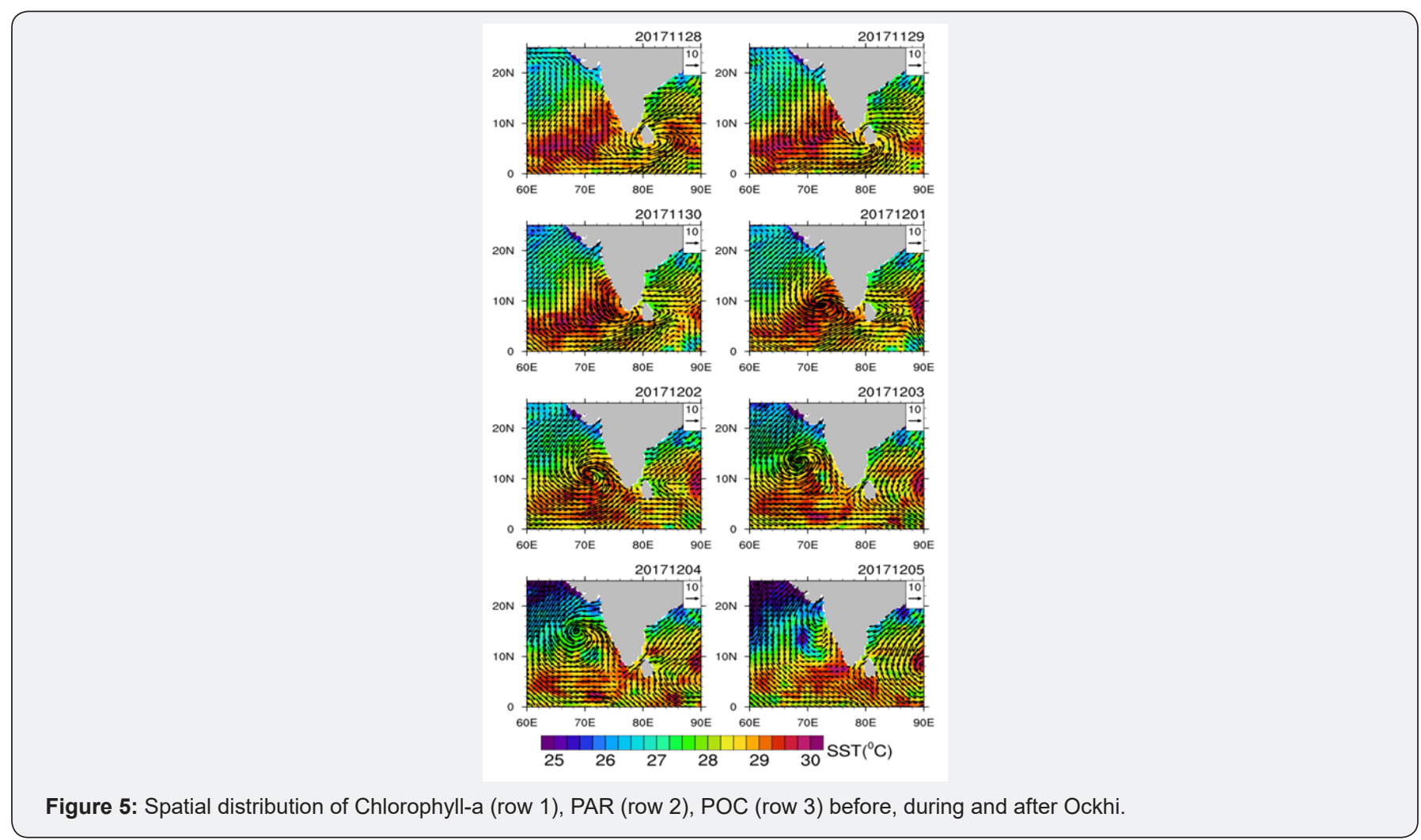

The positive Ekman pumping near the storm centre also became more prominent both in intensity and surface area. During December 3 to 4 , as the storm came under the influence of subtropical westerlies, upwelling was maximum in the same region and thus associated cooling being more prominent. On December 5 , an anomalous cold pool with SST ranging from 26.5 to less than $25^{\circ} \mathrm{C}$ is observed near the region where Ockhi had maximum intensity and underwent re-curvature [20]. The region of cold SST anomaly is called cold patch, which lies between 10$15^{\circ} \mathrm{N}$ and $67-75^{\circ} \mathrm{E}$. Thus, by comparing SST, surface wind, wind stress curl and Ekman pumping, one can clearly see that, surface wind is maximum on December 2, which in turn increases the wind stress curl to more than $4 \mathrm{~N} / \mathrm{m}^{3}$ on December 3 leading to strong upwelling [21]. The effect of this wind stress on SST by anomalous cooling over the region with a spatial scale of 100 to $400 \mathrm{~km}$ is observed to begin one day after intensification of the storm to VSCS and wind stress curl is found to decrease after December 4, resulting in reduced upwelling along the storm track. Lin et al. [13] reported similar SST evolution and its link to wind stress curl over the Western Pacific during the passage of typhoons.

The latent (Figure 6) and sensible heat fluxes (Figure 7) during the life cycle of Ockhi is presented in supplementary file. The latent heat flux values in the order of 250 to $300 \mathrm{Wm}^{-2}$ before the genesis of the cyclone increased to 300 to more than $350 \mathrm{Wm}^{-2}$ during rapid intensification. Sensible heat flux values initially ranged between 15 to $30 \mathrm{Wm}^{-2}$ and later increased over the entire South Arabian sea as Ockhi propagated northwestward. The highest values are seen over the storm area.

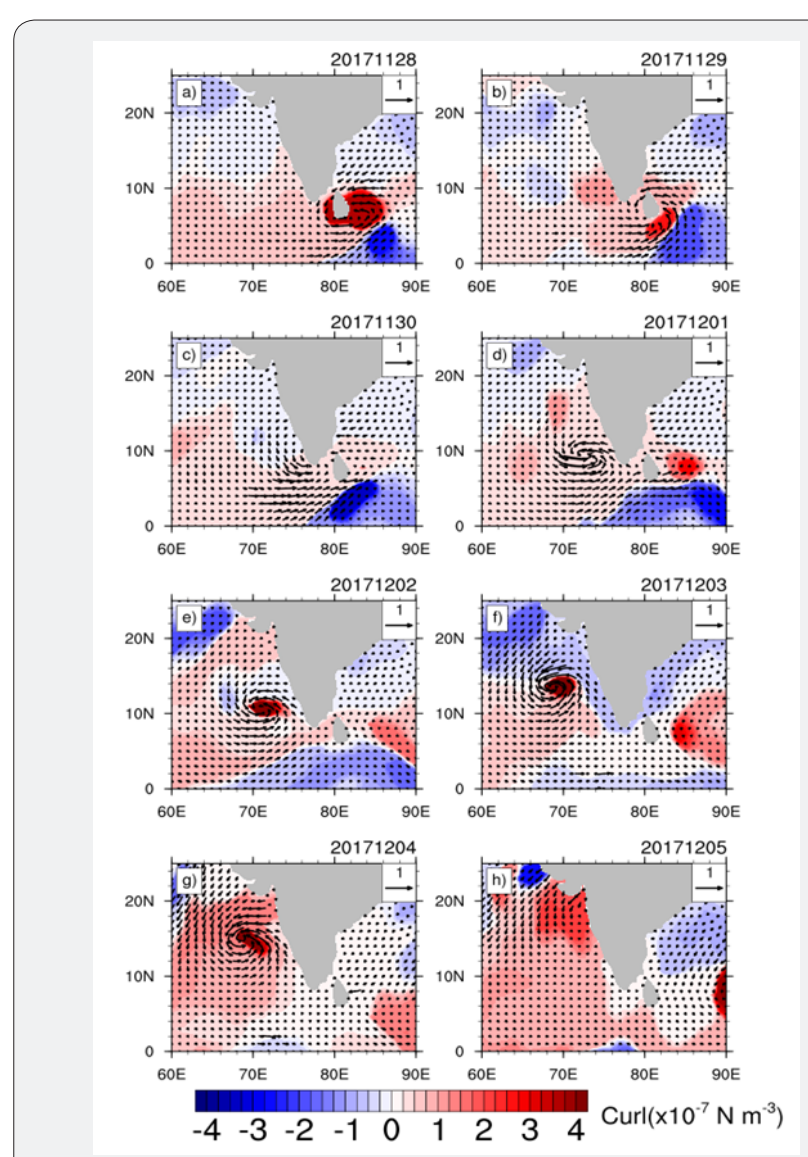

Figure 6: $10 \mathrm{~m}$ surface wind stress curl (shaded) and wind vector for Ockhi from November 28 (a) - December 5 (h), 2017 


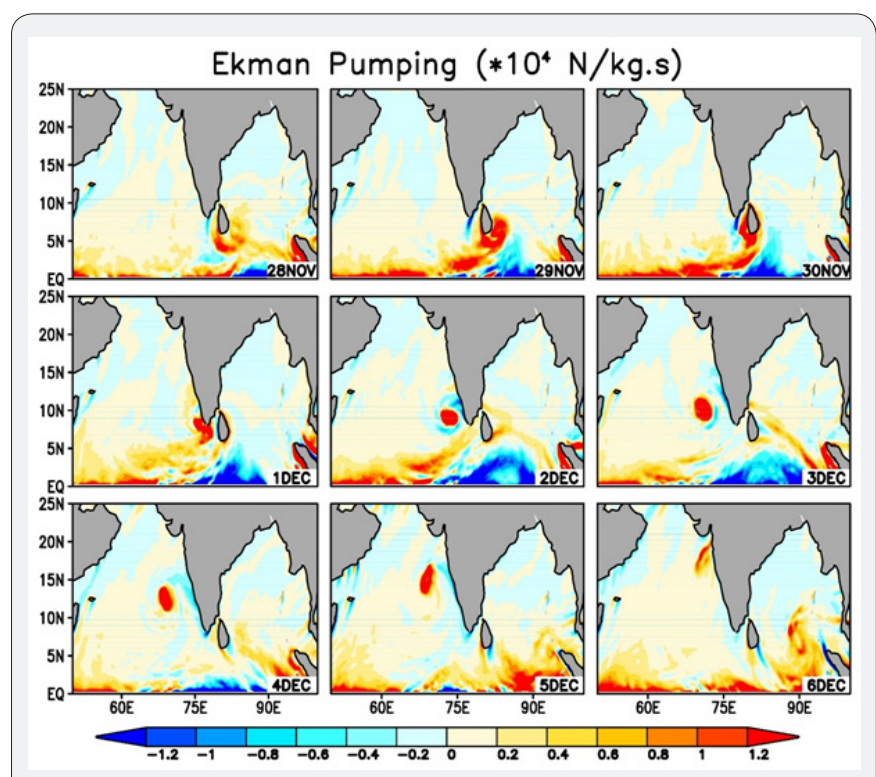

Figure 7: Ekman pumping in ( $\times 104 \mathrm{~N} / \mathrm{kgs})$ during the life cycle of Ockhi.

\section{Impact on Ocean Primary Productivity}

The changes in surface chlor-a, daily averaged PAR and POC concentrations before, during and after the passage of Ockhi are shown in Figure 4. Due to spatial discontinuity in the satellite swath, 8-day average values of the data are used for analysis. 8-day composite values during November 18-26 is taken for analysing the ocean state before storm, 8-day composite during November 27 to December 4 represents the data during the active period of the storm and composite during December 5 to December 12 is considered to study the impact after the storm passage. The area between $10-20^{\circ} \mathrm{N}$ and $65-75^{\circ} \mathrm{E}$ covers the path traversed by Ockhi. The area impacted by cyclone is marked using red ellipse in Figure 4. Low concentration of Chlor-a is found over the area before the passage of the cyclone accompanied by high values of PAR and low POC concentrations [22]. During the active period of the cyclone, Chlor-a was completely absent over the area under the influence of the storm. The primary productivity might have also been influenced by low values of PAR, mostly due to overcast sky associated with Ockhi. Due to the reduction in Chlor-a and PAR, POC was also absent during the period when storm was active.

Upper ocean dynamical and thermodynamically response to cyclone passage is more pronounced after the passage of the cyclone. As evident from, the wind stress curl started increasing from 1 December to 4 December. In response to these high values of wind stress curl and hence storm induced upwelling, sea surface over the regions through Ockhi passed started to cool after December 4. This delayed response is quite common, however the wind speed dependency and slow propagation of Ockhi also contributed to the large values of wind stress curl during this period as previously reported by Lin et al., 2003 over Western Pacific. After December 4, chlor-a concentration increases to more than $5 \mathrm{mgm}^{-3}$ along the storm track where extreme cooling was observed from AVHRR-SST analyses. As the System moved further north, PAR levels also increased to 45-49 einsteinm ${ }^{-2}$ day $^{-1}$ over equatorial Indian Ocean along with decrease in cloud cover. Similarly, POC concentrations also increased during the period from the range of 10-100 to 190-370 mgm $^{-3}$ near this cold patch. The latent (Figure 8) and sensible heat fluxes during the life cycle of Ockhi is presented in supplementary file. The latent heat flux is in the order of 250 to $300 \mathrm{Wm}^{-2}$ before the genesis of the cyclone, which increased to 300 to more than $350 \mathrm{Wm}^{-2}$ as the storm underwent rapid intensification. During genesis, sensible heat flux values range between 15 to $30 \mathrm{Wm}^{-2}$ and later increased over the entire South Arabian Sea as Ockhi propagated northwestward. The highest values are seen over the storm area.

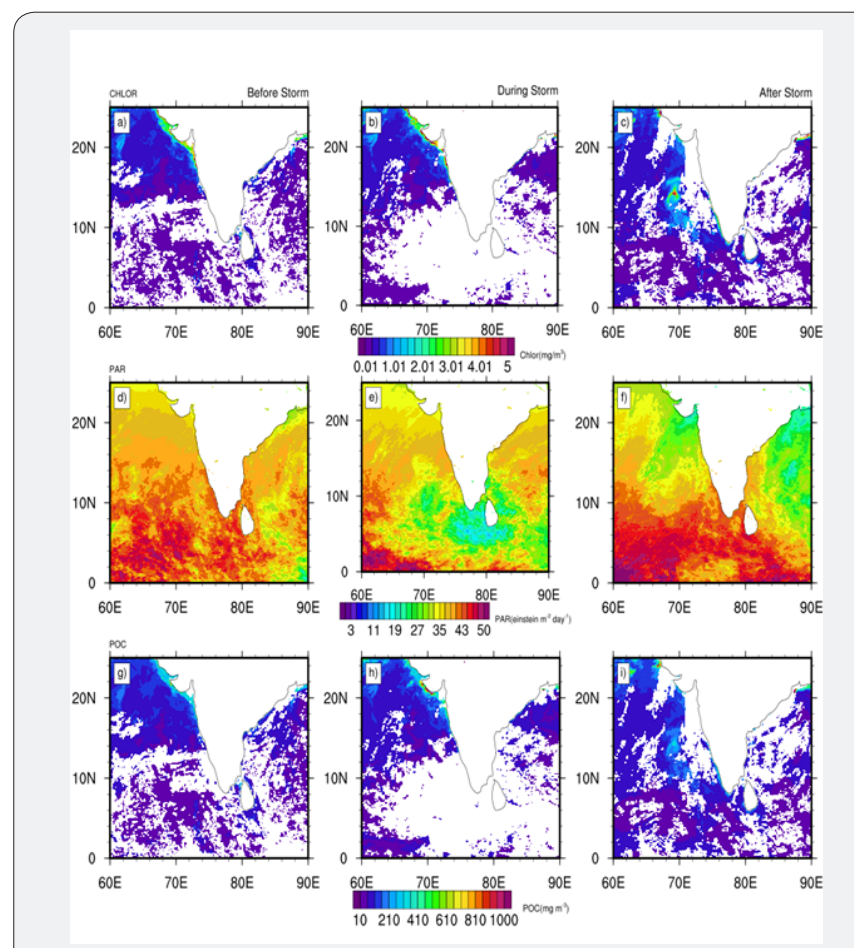

Figure 8: Spatial distribution of Chlorophyll-a (row 1), PAR (row 2), POC (row 3 ) before, during and after the passage of Ockhi.

\section{Conclusion}

The upper ocean response over the Arabian Sea due to the passage of VSCS Ockhi is examined using visible, IR and microwave channels of multiple satellites. Large area of cooling developed in the east-central Arabian Sea in response to high wind stress curl and stronger upwelling due to Ekman transport over regions where the storm had maximum intensity and minimum translational speed. The increase in upwelling is associated with enhanced Ekman pumping and uplifting of thermocline. Increase in wind-stress curl associated with high surface wind clearly led to the reduction in SST followed by increase in PAR, resulting in high concentrations of Chlor-a and associated enhancement of plankton population along the track of Ockhi. It is evident that wind stress induced upwelling and cold patch of SST along with increase in PAR indeed lead to 
higher Chlor-a and POC concentrations in the region of maximum storm intensity and minimum translational speed. A delay of 1-2 days is observed between the maximum wind-stress curl and maximum Chlor-a and POC concentrations. Increased cloud cover might have contributed to the reduction in PAR values during the active periods of the storm and hence to the delay in attaining maximum primary productivity as evident from peak Chlor_a and POC concentrations. The study underlines the potential of combined use of remotely sensed data from multiple sources for carrying out impact assessment of intense weather events occurring over oceanic regions.

\section{Acknowledgement}

The Multi-Satellite datasets used are listed in the references and plotting interfaces (GrADs, NCL, Ferret etc) are gratefully acknowledged. Data from the ERA5 analysis were generated using the Copernicus Climate Change Service and are publicly available on the ECMWF website. SGS is thankful to SPPU for PhD admission and IITM for research fellowship. SA acknowledge the facilities provided under SAC/EPSA.

\section{References}

1. Webster PJ, Holland GJ, Curry JA and Chang HR (2005) Changes in Tropical Cyclone Number, Duration, and Intensity in a Warming Environment. Science 309(5742): 1844-1846.

2. Murakami H, Vecchi GA and Underwood S (2017) Increasing frequency of extremely severe cyclonic storms over the Arabian Sea. Nature Climate Change 7(12): 885.

3. Dunkerton TJ, Montgomery MT, Wang Z (2008) Tropical cyclogenesis in a tropical wave critical layer: Easterly waves. Atmospheric Chemistry and Physics Discussions 8(3): 11149-11292.

4. Rajasree VPM, Kesarkar AP, Bhate JN, Umakanth U, Singh V, et al. (2016) Appraisal of recent theories to understand cyclogenesis pathways of tropical cyclone Madi (2013). Journal of Geophysical Research: Atmospheres 121(15): 8949-8982.

5. Yanai M, (1964) Formation of tropical cyclones. Reviews of Geophysics 2(2): 367-414.

6. Price JF (1981) Upper ocean response to a hurricane. Journal of Physical Oceanography 11(2): 153-175.

7. Latha TP, Rao KH, Nagamani PV, Amminedu E, Choudhury SB, et al. (2015) Impact of Cyclone PHAILIN on Chlorophyll-a Concentration and Productivity in the Bay of Bengal. International Journal of Geosciences 6(05): 473.
8. Lin I, Liu WT, Wu CC, Wong GT, Hu C, et al. (2003a) New evidence for enhanced ocean primary production triggered by tropical cyclone. Geophysical Research Letters 30(13).

9. Shibano R, Yamanaka Y, Okada N, Chuda T, Suzuki SI, et al. (2011) Responses of marine ecosystem to typhoon passages in the western subtropical North Pacific. Geophysical Research Letters 38(18).

10. Subrahmanyam B, Rao KH, Srinivasa Rao N, Murty VSN and Sharp RJ (2002) Influence of a tropical cyclone on chlorophyll-a concentration in the Arabian Sea. Geophysical Research Letters 29(22).

11. Vinayachandran PN and Mathew S (2003) Phytoplankton bloom in the Bay of Bengal during the northeast monsoon and its intensification by cyclones. Geophysical Research Letters 30(11).

12. Zheng ZW, Ho CR and Kuo NJ (2008) Importance of pre-existing oceanic conditions to upper ocean response induced by Super Typhoon HaiTang. Geophysical Research Letters 35(20).

13. Lin II, Liu WT, Wu CC, Chiang JC and Sui CH (2003b) Satellite observations of modulation of surface winds by typhoon-induced upper ocean cooling. Geophysical research letters 30(3).

14. Janowiak JE, Joyce RJ and Yarosh Y (2001) A real-time global halfhourly pixel-resolution infrared dataset and its applications. Bulletin of the American Meteorological Society 82(2): 205-217.

15. ISRO MOSDAC, SCATSAT-1 (2016): https://mosdac.gov.in/content/ Mission/scatsat-1

16. NASA Goddard Space Flight Center (2014a) MODIS-Terra Ocean Color Data; NASA Goddard Space Flight Center, Ocean Ecology Laboratory, Ocean Biology Processing Group.

17. NASA Goddard Space Flight Center (2014b) MODIS-Terra Ocean Color Data; NASA Goddard Space Flight Center, Ocean Ecology Laboratory, Ocean Biology Processing Group.

18. Montgomery MT, Nicholls ME, Cram TA and Saunders AB, LL Lussier III, et al. (2010) The genesis of Typhoon Nuri as observed during the Tropical Cyclone Structure 2008 (TCS-08) field experiment-Part 1: The role of the easterly wave critical layer. Atmos Chem Phys 10: 98799900.

19. Emanuel K (2005) Increasing destructiveness of tropical cyclones over the past 30 years. Nature 436(7051): 686-688.

20. Gray WM (1979) Hurricanes: Their formation, structure and likely role in the tropical circulation. Meteorology over the tropical oceans.

21. India Meteorological Department, Tropical Cyclones - Frequently Asked Questions.

22. India Meteorological Department (2017) Very Severe Cyclonic Storm "Ockhi" over Bay of Bengal: A Report 


\section{Your next submission with Juniper Publishers} will reach you the below assets

- Quality Editorial service

- Swift Peer Review

- Reprints availability

- E-prints Service

- Manuscript Podcast for convenient understanding

- Global attainment for your research

- Manuscript accessibility in different formats ( Pdf, E-pub, Full Text, Audio)

- Unceasing customer service

Track the below URL for one-step submission https://juniperpublishers.com/online-submission.php 